\title{
LA INFLUENCIA DE LO QUECHUA EN LA NARRATIVA DE ARGUEDAS: UN ACERCAMIENTO A SUS RELATOS
}

\author{
GRACIA MORALES \\ Universidad de Granada (España) \\ graciam@ugr.es
}

\section{RESUMEN}

El presente trabajo aborda la importancia de la presencia formal de lo quechua en la cuentística de José $\mathrm{M}^{a}$ Arguedas. Primeramente se analiza cómo este idioma influye en la narrativa del peruano, tanto a nivel léxico, como morfológico o gramatical. Después, siempre tomando como ejemplo sus relatos, revisamos los mecanismos que el autor utiliza para hacer entrar en sus textos otro elemento propio de la expresión quechua: la oralidad. Entendemos, finalmente, la producción de Arguedas como un discurso esencialmente transculturado y en conflicto, ante la difícil empresa de conjugar dos formas de expresión opuestas: la blanca/española/escrita, frente a la indígena/quechua/oral.

Palabras clave: José $\mathrm{M}^{\mathrm{a}}$ Arguedas, cuentos, transculturación, oralidad.

\section{ABSTRACT}

This article deals with the importance of the formal presence of Quechua in the storytelling of José María Arguedas. First, we analyze how this language influences the narrative of the Peruvian, in lexical, morphological and grammatical aspects.

Then, always taking his stories as an example, we review the mechanisms used by the author to introduce elements of the Quechua orality into his own texts. We understand, finally, the production of Arguedas like a speech essentially in conflict and transcultural, since he tries to combine two opposite forms of expression: the white / Spanish / written, against indigenous / Quechua / oral.

Keywords: José $\mathrm{M}^{\mathrm{a}}$ Arguedas, storytelling, transcultural, orality.

Español / quechua: dos idiomas, dos sistemas culturales

Como sabemos, la obra arguediana surge desde una raíz heteróclita y plural, que trata de poner en comunicación dos ámbitos culturales distintos e, incluso, opuestos: el mundo blanco frente al indígena. En Perú, estos dos espacios ideológicos se concretan en dos idiomas distintos (español/quechua) y dos modos de comu- nicación (escritura/oralidad). De este modo, textualmente, encontrar una forma de imbricar los dos idiomas, equivalía a estar construyendo un producto transculturado, de coexistencia de estas dos realidades.

El protagonismo que Arguedas concederá a lo largo de toda su vida a la reflexión sobre el quechua, así como al factor del bilingüismo en el Perú, encuentran su razón de ser en esa afirmación de que el uso de una lengua especí-
Gracia Morales Ortiz

(Motril, 1973) es profesora de la

Universidad de Granada. Su labor investigadora se centra, sobre todo, en la narrativa y el teatro hispanoamericanos del siglo XX. Su tesis doctoral, Arguedas y Cortázar: dos búsquedas de una identidad latinoamericana, obtuvo el Premio Extraordinario de Doctorado. Sobre Arguedas ha publicados varios trabajos, entre los que destaca su libro José $M^{a}$ Arguedas: el reto de la dualidad cultural (2011). Es además poeta y dramaturga, habiendo obtenido en esta última faceta un importante reconocimiento.
La influencia de lo quechua en la narrativa de Arguedas: un acercamiento a sus relatos GRACIA MORALES 

Tras haber dado a conocer algunos cuentos sueltos en revistas en 1934 y 1935 («Los comuneros de Ak'ola», "Los comuneros de Utej-Pampa», "K'ellk'atayPampa», «El vengativo», «E cargador»), Agua es el primer libro donde reúne varios relatos. Aparece en Lima, editado por la Compañía de Impresiones y Publicidad, en 1935, y lo componen tres textos: "Agua», «Los escoleros» y "Warma kuyay». Nosotros daremos constancia de dónde y cuándo se publicaron por primera vez los cuentos comentados, aunque, para las citas, utilizaremos algunas recopilaciones posteriores, recogidas en la bibliografía.
La influencia de lo quechua en la narrativa de Arguedas: un acercamiento a sus relatos GRACIA MORALES fica implica una serie de factores que superan lo meramente fonético, léxico o gramatical. Encontrar, por tanto, la manera de que ambos sistemas lingüísticos habiten en el discurso, supone una forma de estar favoreciendo la convivencia de esos dos sistemas culturales.

En este trabajo pretendemos centrar nuestra atención en uno de los aspectos que nos ha parecido más significativos de la narrativa arguediana: su conexión con la lengua quechua. Nuestra intención es analizar la obra cuentística de este autor para entender cómo se produce el rescate de ese idioma, esencialmente ágrafo, y cuáles son los mecanismos utilizados para que la escritura sea capaz de sustentarlo y revelarlo, sin dejar de ser asumible para el lector occidental.

¿Cómo descubrir esas aldeas, pueblos y campos; en qué idioma narrar su apacible y a la vez inquietante vida? ¿En castellano? ¿Después de haberlo aprendido amado y vivido por medio del dulce y palpitante quechua? Fue aquel un trance al parecer insoluble (Arguedas, 1992, p. 33).

Sin embargo, sí que encontró finalmente un sistema para introducir lo quechua en el interior de un discurso escrito en español. Vamos a destacar dos cuestiones cuya importancia nos parece fundamental: la influencia del quechua sobre el español y la codificación escrita de determinados registros orales. Realmente, estos dos elementos están indisolublemente unidos, como iremos viendo, pues el uno está implicando necesariamente al otro.

\section{La influencia del quechua sobre el español. El léxico}

La forma más directa, pero también la más superficial, de hacer que el quechua esté presente en sus textos consiste en introducir términos en ese idioma. Esto ocurre cotidianamente en la producción arguediana. Hay que aclarar que el narrador se encarga, en bastantes ocasiones, de traducirnos ese léxico, bien introduciendo su referente español entre paréntesis, bien explicando su significado en nota a pie de página. Sería impensable proporcionar aquí un listado de los vocablos quechuas que encontramos en la cuentística arguediana. Damos noticia de los que aparecen con mayor asiduidad en su primer libro de relatos, Agua ${ }^{1}$, para que sirvan como muestra de su énfasis en este recurso estilístico. Ofrecemos un listado con su respectiva traducción, cuando ésta aparece expresa, dividiéndolos en tres grupos principales.

Términos de uso cotidiano:

mak'tillos y pasñas (muchachos y mujeres jóvenes), lok'os (sombreros), llak'ta (pueblo), uma (cabeza), witron (patio grande), wiksa (barriga).

Animales, plantas y otros términos referentes a la naturaleza:

vacas allk'as, pillkas, k'erk'ales, atok' (zorro), allk'o (perro), k'ocha (estanque, laguna), Tayta Inti (sol), Mama-allpa (madre tierra), chascha (perro), chiwako (pájaro), payk'ales, sunchus, kishuares, pichiucha (gorrión), killinchos (cernícalos), taya, ork'o (montaña), ischu.

Términos referidos a elementos culturales quechuas:

dansak' (bailarín), ayarachi (música fúnebre), wikullo (arma arrojadiza), wak'tay (lucha a zurriago entre solteros en carnavales), sanki (el poncho del gigantón), troya, lek'les, ak'tok, tinka (boliche), kuchi mansay (amansar chanchos), jarawi.

En estos mismos relatos también se introducen determinadas expresiones en quechua, que no son sustantivos, sino oraciones o sintagmas, expresados casi siempre cuando algún personaje tiene un momento de exaltación emocional; encontramos, así, insultos, órdenes, interjecciones, etc. Por ejemplo, detectamos ese uso en imperativos como «k'allary», que significa «comienza», o «jkutirimuychic mak'takuna!», traducido por «ivolved, hombres, volved!»; también se utiliza el quechua para insultar al patrón «¡sua!» («jladrón!») y «¡wikuñero allk’o!» («perro cazador de vicuñas»); en expresiones de regocijo («jjajayllas!» o «iyaque!»), etc. Estos últimos ejemplos nos recuerdan un comentario del propio Arguedas donde afirmaba la expresividad de ese idioma indígena y cómo incluso los mistis lo utilizaban en los momentos de mayor emotividad:

Los que hablamos este idioma sabemos que el kechwa supera al castellano en la expresión de algunos sentimientos que son lo más característico del alma indígena: la ternura, el cariño, el amor a la naturaleza. El kechwa logra expresar todas las emociones con 
igual o mayor intensidad que el castellano. Los mismos principales, despreciadores del indio, cuando sienten una gran emoción dejan el castellano para hablar en kechwa, y en ese rato se desahogan con más violencia, como quien habla con sus propias palabras (1938, p. 28).

En este sentido, resulta curioso recoger las reflexiones que a lo largo de los cuentos arguedianos se incluyen sobre el propio gesto de nombrar. En alguna ocasión, los personajes de estos relatos hacen mención de la cualidad esencialista que para ellos tiene la forma en que se designa cualquier realidad; en su concepción, ésta no es arbitraria, sino plena de significado. Por ejemplo, así se nos narra en «Los escoleros»: «La Gringa era la mejor vaca del pueblo [...] La llamaron Gringa porque era blanca entera y poco legañosa» (1983, p. 41).

$\mathrm{Y}$ en el cuento «El barranco» dice el narrador:

La Ene madre del Pringo, era la vaca más lechera de la señora Grimalda. [...] La llamaban Ene porque en el lomo negro tenía dibujada una letra $\mathrm{N}$, en piel blanca. [...]

Esta vez, su cría era el Pringo. La vaquera lo bautizó con ese nombre desde el primer día. El Pringo, porque era blanco entero. El Mayordomo quería llamarlo Misti, porque era el más fino y el más grande de todas las crías de su edad (1983, p. 90).

También los topónimos suelen ser justificados. En «K'ellk'atay-Pampa» afirma un personaje, refiriéndose al río Yanamayu:

¿Sabes, Nicacha? A este río le pusieron ese nombre porque es malo. Yanamayu, alma negra, asesino. Nadie le quiere en la pampa de Yanamayu, ni las ovejitas, ni las vacas, ni los caballos cerriles; con odio le oyen roncar todo el año. Los viajeros le tiemblan, es enemigo de los viajeros. En diciembre se llevó al chiquito de don Apa; se salió -dicen- y con un brazo le arrastró de la cintura y lo envolvió entre su barro negro; Yanamayu nos busca a nosotros los mak'tillos. ¡Yanamayu odioso! (1973, p. 27).

Según vamos viendo, la palabra no sólo alude convencionalmente al objeto, siguiendo una definición sausseareana del lenguaje, sino que la palabra «es» el objeto: existe una relación de interdependencia necesaria entre significado y significante. Ese principio explica, por ejemplo, el hecho de que muchos nombres quechuas se construyan mediante composición, según se testimonia en los mismos cuentos de Arguedas: «Orolvica» significa «gusano sagrado», según nos explica el narrador de ese relato; Singu bautiza a su perro como «Hijo Solo»; «Rasu-Ñiti» quiere decir «que aplasta nieve» y su sucesor, el joven «Atok' sayku», equivale a "que cansa el zorro». Es decir, en la formación de vocablos ya está interviniendo un factor explicativo, definitorio de la naturaleza del referente.

Ello ocurre porque el pensamiento indígena que sostiene las prácticas cotidianas de estas sociedades, y que también influye en su construcción de un lenguaje, está regido por la ley de la analogía y la metamorfosis. Para ver cómo se produce este tipo de transformaciones e influencias, recogemos un fragmento de «Los escoleros», donde el niño Ernesto verbaliza ese proceso por el cual un objeto puede influir sobre una realidad que, desde un planteamiento lógico (no analógico), debería serle ajena:

Miré la pared de una casa sin techo; hacía muchos años que esa pared nueva esperaba que le pusieran tejado. A dos metros del suelo, el albañil había hecho poner, por capricho, una piedra casi redonda; los escoleros le pintaron ojos, nariz y boca; y desde entonces la piedra se llamó Uma (cabeza).

- ¡Uma de Don Ciprián!

Me agaché, como en el barranco de Wallpamayu, agarré la piedra por una punta, encogí mi brazo, lo templé bien, y tiré después. La piedra se despedazó en un filo de la Uma, mordiéndole el extremo de la frente. [...] Como alocado le hablé a la piedra, a una Uma; le amenacé furioso (1983, pp. 44-45).

Es muy interesante percatarse de las sucesivas transformaciones a que se somete la piedra, simplemente mediante la verbalización: primero se la metamorfosea en una Uma (cabeza) al comenzar a llamar así; pero después, el protagonista, al gritar « $i$ Uma de Don Ciprián!», la dota de una identidad nueva y por eso la amenaza e intenta dañarla, como si estos gestos afectaran al físico real de ese otro personaje.

Nombrar algo es convertirlo en el significado que ese nombre le aporta. Por consiguiente, cobran una cualidad muy especial oraciones que, desde una apreciación occidentalizada, parecerían tautologías, como la inolvidable frase con la que se cierra «La agonía de Rasu-Ñiti»²,

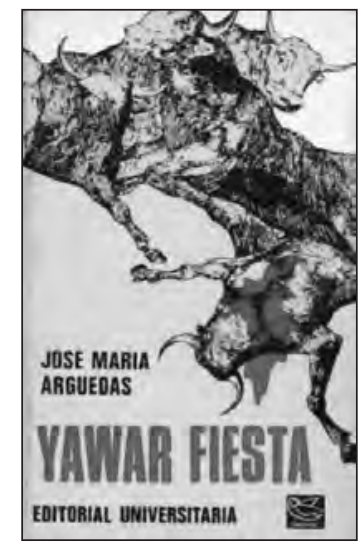

2

Relato publicado por primera vez en 1962, en Talleres Gráficos Ícaro, de Lima.

La influencia de lo quechua en la narrativa de Arguedas: un acercamiento a sus relatos GRACIA MORALES 


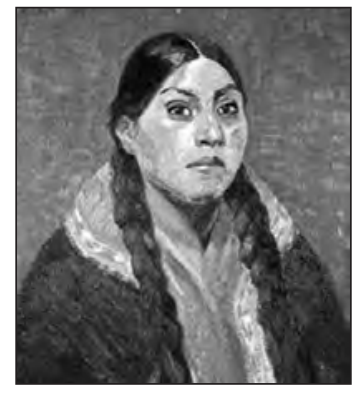

La Santusa, José Sabogal

3

La recopilación Amor mundo y todos los cuentos aparece en Lima (editorial Juan ÁlvarezFrancisco Moncloa) en 1967. En ella se recogen los relatos que compusieron Agua, algunos que se habían ido publicando sueltos («El barranco» (1939), «Orovilca» (1954), «La muerte de los Arango» (1955), «Hijo solo» (1957), "La agonía de Rasu-Niti» (1962), «El forastero» (1964)), y otros cuatro nuevos, bajo el título "Amor mundo»: se trata de «El horno viejo», «La huerta», «El ayla» y «Don Antonio».

La influencia de lo quechua en la narrativa de Arguedas: un acercamiento a sus relatos GRACIA MORALES cuando la hija del difunto afirma: «-Por dansak' el ojo de nadie llora. Wamani es Wamani» (1983, p. 141).

También nos ha llamado la atención descubrir el parentesco entre lo mágico-religioso y el idioma quechua, que llega a ser algo presente incluso en los sacerdotes blancos. En conexión con esa forma de sincretismo que tanto ha llamado la atención a los estudiosos de este subcontinente, también en los relatos de Arguedas se testimonia cómo los curas cristianos, en determinados momentos, utilizan la lengua indígena, tal vez por una mayor confianza en sus poderes milagrosos. Por ejemplo, así ocurre en el cuento del libro Amor mundo ${ }^{3}$, titulado «La huerta»:

- ¡El Arayá me va a limpiar, seguro! Me voy, me voy. Deme su bendición, padrecito. -rogó el chico.

- Sí, cómo no; contra las serpientes del cerro, no contra tu cuerpo sucio: «En nombre del Padre, del Hijo, del Espíritu Santo...».

Tarde se dio cuenta el sacerdote de que le había dado la bendición en quechua: «Dios Yaya, Dios Churi, Dios Espíritu Santo...» (1983, p. 160).

Y también nos parece muy llamativa la secuencia final del relato «La muerte de los Arango", donde se nos presenta un ritual extrañamente mixto de cristianismo y paganismo para acabar con la peste:

Don Jáuregui cantó en latín una especie de responso junto al «trono» de la Virgen, luego se empinó y bajó el tapaojos, de la frente del tordillo, para cegarlo.

- ¡Fuera! -gritó-. ¡Adiós calavera! ¡Peste!

Le dio un latigazo, y el tordillo saltó al precipicio. Su cuerpo chocó y rebotó muchas veces en las rocas, donde goteaba agua y brotaban líquenes amarillos. Llegó al río; no lo detuvieron los andenes filudos del abismo.

Vimos la sangre del caballo, cerca del trono de la Virgen, en el sitio en que se dio el primer golpe.

- ¡Don Eloy, Don Eloy! ¡Ahí está tu caballo! ¡Ha matado a la peste! En su propia calavera. ¡Santos, santos, santos! ¡El alma del tordillo recibid! ¡Nuestra alma es salvada! ¡Adies millahuay, despidillahuay...! (¡Decidme adiós! ¡Despedidme...!).

Con las manos juntos estuvo orando un rato, el cantor, en latín, en quechua y en castellano (1983, p. 120).

De este modo, los rituales se amalgaman, pero lo hacen también en un ámbito lingüísti- co: las lenguas se solapan como demostración de que se están imbricando las culturas y los pensamientos que han generado cada una de ellas. Así pues, la aparición del léxico quechua consigue trasladar al lector hacia ese espacio indígena al que no pertenece, logra desplazarlo y romper, de algún modo, sus hábitos occidentales de lectura.

\section{La influencia del quechua sobre el español: morfología y sintaxis}

Ahora bien, como ya hemos apuntado, el léxico puede ser considerado el nivel más superficial de presencia del idioma quechua en estos textos. Ocurre también que la morfología y la sintaxis de dicha lengua se insertan de un modo más profundo, dotando a las frases y los vocablos en castellano de un hálito especial, sobre todo en sus primeros relatos. En opinión de Leónidas Morales,

el principio que orientó la creación del nuevo lenguaje Arguedas lo halló actuando en la realidad cotidiana misma del Perú. En efecto: lo adivinó en el «desgarro» que sufrían en el proceso de incorporación a la lengua quechua las escasas palabras castellanas que los indios alcanzaban a aprender en sus propias aldeas. En estos desgarros, que son todo un proceso de absorciones y eliminaciones, de integraciones selectivas, está en estado de germen, como latencia o virtualidad, el fenómeno de simbiosis lingüísticocultural que representa el estilo de Arguedas (1993, p. 155).

Es muestra de este tipo de influencia los casos en que a una palabra española se la sufija con una partícula quechua; esto ocurre especialmente con el plural «-kuna»y con el diminutivo «-cha» e «-y». Casi todos los nombres referidos a pueblos indígenas que aparecen en Agua están formados así: los Sanjuankuna, los Tinkikuna, los Ayalaykuna, y también aparece la expresión « Suakuna!» («ladrones») o en «mak'takuna («niños»); en cuanto al diminutivo, será una constante acompañando a los nombres propios de la mayoría de los niños o de personajes queridos por el narrador (en ese mismo relato aparece «Pantaleoncha», "Pantacha», «Ramoncha», «Bankucha», «Vicenticha», y en el siguiente «Juancha», «Teofacha», etc...), pero también se utiliza al referirse a animales ("Gringacha», Kaisercha»), y en palabras de uso cotidiano: 
«Taytacha» (Tayta es «señor» o «dios»), «misticha», «mamacha», «inticha» (Inti es «sol»)... Los ejemplos serían innumerables; lo que nos interesa destacar es cómo estas palabras se cargan de connotaciones de ternura y cariño cuando el narrador o los personajes le añaden la terminación quechua.

Pero, curiosamente, esta misma tendencia hacia la utilización de diminutivos repercute sobre el español: nos referimos a que, sin tener que utilizar el ya citado «-cha», también es muy habitual que se use el -ito/-ita castellano. Resulta francamente llamativo el uso reiterado de este tipo de sufijación. Sólo en el cuento «Agua» podemos recoger su aparición en palabras como "solita», "pueblecito", «casitas», «caritas», «vaquillas», «traguito», «terrenitos», «mak'tillos», «chanchito», «mujercitas», «chacrita», «cholillos», «torrecita», «criaturitas», «maizalitos», «balitas», «vaquita», «papalitos», «tempranito», «tiendecita», «espejitos», «pajaritos», «pobrecitos», «piedrecitas», «revolvercito», "potrillo», «animalitos», «pueblito»... En nuestra opinión, esta insistencia termina teniendo repercusiones «quechuizantes» sobre la lengua castellana; dicho de otro modo, el diminutivo en este caso es español y la construcción es normativa de esta lengua, pero el que se lo utilice tan reiteradamente parece responder a una significación de raigambre indígena: de este modo, sin trastocar la morfología propia de los blancos, está consiguiendo imprimirle una latencia de lo indio en su interior, porque la mirada sobre esas realidades inertes se empapa de una delicadeza y un mimo, propios de la sensibilidad indígena.

Otro aspecto que ha sido muy destacado por la crítica es cómo ese impacto de un código lingüístico sobre el otro, produce una especie de resquebrajamiento en el uso habitual del español. El propio Arguedas se refirió en varias ocasiones a esta estrategia de «desordenamiento»; así lo recuerda en «La novela y el problema de la expresión literaria en el Perú» aludiendo a sus primeros relatos:

En mi experiencia personal la búsqueda de un estilo fue, como ya dije, larga y angustiosa. Y un día de aquellos, empecé a escribir, para mí, fluida y luminosamente, como se desliza el agua por los cauces milenarios. Concluí el primer relato en pocos días y lo guardé temerosamente. [...]

Muchas esencias, que sentía como las mejores y legítimas, no se diluían en los términos castellanos construidos en forma ya conocida. Era necesario encontrar los sutiles desordenamientos que harán del castellano el molde justo, el instrumento adecuado (1992, pp. 33-34).

Y añade más tarde:

¿En qué idioma se debía hacer hablar a los indios en la literatura? Para el bilingüe, para quien aprendió a hablar en quechua, resulta imposible, de pronto, hacerlo hablar en castellano; en cambio quien no los conoce mediante la niñez, la experiencia profunda, puede quizá concebirlos expresándose en castellano. Yo resolví el problema creándoles un lenguaje castellano especial, que después ha sido empleado con horrible exageración en trabajos ajenos. ¡Pero los indios no hablan en ese castellano ni con los de lengua española, ni mucho menos entre ellos! Es una ficción. Los indios hablan en quechua (1992, p. 34).

Varios autores se han encargado de estudiar los mecanismos linguísticos utilizados por Arguedas para construir ese castellano «especial» ${ }^{4}$. Resumiendo algunas de sus características, Bendezu Aibar señala:

Entre los procedimientos lingüísticos que Arguedas utilizó, señalamos como muestra los siguientes: el ordenamiento sintáctico quechua, que produce en español hipérbatos formidables; la incorporación de palabras quechuas sin equivalente español, que no es lo mismo que los anglicismos y galicismos de los personajes cosmopolitas de Cortázar, por ejemplo; «el elemento castellano» de los indios a que alude Arguedas y que en la realidad cumple más bien sólo una función fática o sea de contacto o de apertura del circuito de la comunicación lingüística a partir del quechua; y también, lo que es muy importante, la inserción de canciones quechuas que cumplen importante función poética y semántica dentro del texto de la novela (1974, p. 23).

Por su parte, observa Castro Klarén:

El español salpicado de quechua y la rara dicción del narrador $\mathrm{y}$ de algunos personajes producen un cierto velo entre la palabra y la realidad. [...] Este mundo descrito a través de extraña sintaxis, de la acumulación de un vocabulario desconocido e inaccesible al lector común, adquiere una cualidad lejana y exótica. Esa misma cualidad, sin embargo, refuerza la validez del mundo novelado para los lectores familiarizados con la vida de la sierra del Perú (1973, pp. 55-56).

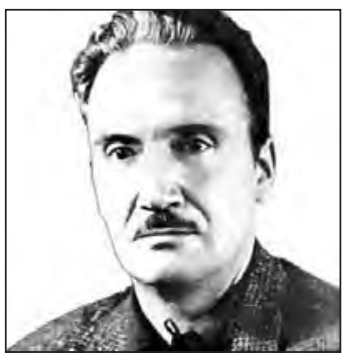

José María Arguedas

4

Para un análisis más minucioso, aconsejamos consultar, por ejemplo, Aleza Izquierdo (1997).
La influencia de lo quechua en la narrativa de Arguedas: un acercamiento a sus relatos GRACIA MORALES 


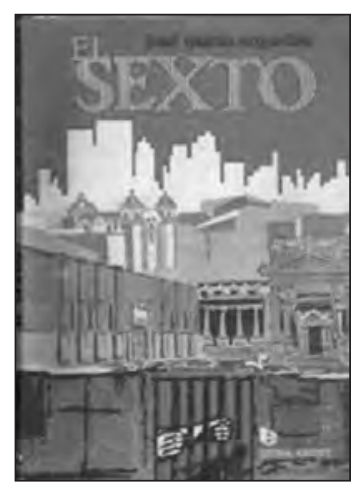

También Rowe analizó acertadamente algunas de esas especificidades del castellano utilizado por Arguedas, sobre todo en sus primeros libros, afirmando:

El quechua es un idioma con inflexiones, es decir, uno en el cual se utilizan terminaciones y casos para expresar relaciones que en el español o el inglés se definen por medio de artículos, pronombres, preposiciones y conjunciones. En Agua, la visión del mundo genérica, no individualizada, del indio, se sugiere por medio de la omisión de artículos, el uso del gerundio con preferencia sobre las usuales formas verbales personales y una dislocación general del orden de las palabras, de modo que el verbo en la frase es colocado mucho más atrás de lo que es normal en español: los elementos de la oración tienden así a combinarse e interactuar en un plano diferente de aquel de la acción individualizada. Estos procedimientos, junto con una tendencia a omitir las conjunciones, reproduce en español algo del carácter especial del quechua (1973, p. 5).

Según expone este mismo crítico en un trabajo posterior, la elipsis de los artículos resulta ser un mecanismo fundamental, pues provoca en el lector la sensación de estar frente a unas categorías de pensamiento distintas, de tal modo que «se nos da la impresión de una percepción de la realidad en que los objetos parecen tener una presencia más inmediata y se hallan menos conceptualizados que para nosotros» (1979, p. 50).

Este tipo de lenguaje extraño se hace muy palpable en las intervenciones de los personajes indígenas, lo cual puede verse, sobre todo, en los cuentos de Agua y en otros como «El barranco», «Hijo Solo», «La agonía de RasuNiti» o «El ayla». Para ejemplificar este tipo de discurso al que nos venimos refiriendo, sería interesante recoger algunos fragmentos donde queden explícitas estas características. Seleccionamos un diálogo entre Pantaleón y otro indio, llamado Don Wallpa, en «Agua»:

- ¿Acaso? En la costa también, al agua se agarran los principales no más; los arrendatarios lucaninos, wollhuinos, nazqueños, al último ya riegan, junto con los que tienen dos, tres chacritas; como de caridad le dan un poquito, y sus terrenos están con sed de año en año. Pero principales de Nazca son más platudos; uno solo puede comprar a San Juan con todos sus maizales, sus alfalfares y su ganado. Casi gringos no más son todos, carajeros, como a Taytacha de iglesia se hacen respetar con sus peones.
- Verdad. Así son nazcas -dijo el Varayok’ Wallpa. - Como en todas partes en Nazca también los principales abusan de los jornaleros -siguió Pantaleoncha-. Se roban de hombre el trabajo de los comuneros que van de los pueblos: San Juan, Chipau, Santiago, Wallawa. Seis, ocho meses, le amarran en las haciendas, le retienen sus jornales; temblando con terciana le meten en los cañaverales, a los algodonales. Después le tiran dos, tres soles a la cara, como gran cosa. ¿Acaso? Ni para remedio alcanza la plata que dan los principales. De regreso, en Galeras-pampa, en Tullukata, en todo el camino se derrama la gente; como criaturitas, tiritando, se mueren los andamarkas, los chillek'es, los sondondinos. Ahí nomás se quedan, con un montón de piedra sobre la barriga. ¿Qué dicen sanjuankuna?

- ¡Carago! ¡Mistis son como tigre!

- ¡Comuneros son para morir como perro! (1983, pp. 19-20).

En este fragmento pueden evidenciarse muchas de esas características reseñadas anteriormente: desaparición de artículos («Pero principales de Nazca son más platudos», «Ni para remedio alcanza la plata», «Mistis son como tigre", "Comuneros son para morir como perro»), introducción de palabras y sufijos quechuas («Varayok'", «Sanjuankuna», «Taytacha»), colocación de los complementos del verbo al inicio de la oración, desplazando así al sujeto («al agua se agarran los principales no más», «Ni para remedio alcanza la plata»), uso de interjecciones y expresiones de función fática («¿Acaso?»), utilización de adjetivos sin explicitar el sustantivo al que acompañan, de tal modo que se destaca la cualidad como algo esencial («Casi gringos no más son todos, carajeros»), etc...

Para citar algún texto más tardío, hemos escogido la intervención de un muchacho indio en el relato «El ayla», perteneciente a Amor mundo:

- Dicen. ¿¿Quién? Los señores vecinos, pues. Ellos no entran al ayla. No han visto. Por mando del corazón y por mando del gran padre Arayá jugamos; sembramos de noche. Bonito. A ti te conocemos. Te ha pateado, dicen, don Guadalupe cuando eras criatura. [...] La candela del cementerio del pueblo de don Guadalupe quema feo, por siempre. Así dicen (1983, pp. 166-167).

Otra vez encontramos aquí algunos de los usos que caracterizaban al fragmento anterior: el uso libre del adjetivo («Bonito», «quema feo»), anteposición de los complementos y 
colocación del verbo al final («Por mando del corazón y por mando del gran padre Arayá jugamos»), supresión de artículos y pronombres («cuando eras criatura», «No han visto»), muletillas y expresiones de función fática («pues», «dicen»)...

Según hemos expuesto, este tipo de discurso que rompe con la estructura normativa del español es utilizado, sobre todo, por personajes infantiles y por los indígenas o mestizos que recorren sus relatos. El narrador, por su parte, acostumbra a tener un estilo menos elíptico, más ordenado y fluido. Pero también pueden observarse en él ejemplos de este desordenamiento sintáctico, fruto de su implicación con el espacio cultural quechua. Por ejemplo, esto se refleja muy claramente cuando se propone transcribir el pensamiento directo de algún personaje, en una forma cercana al llamado «monólogo interior»:

Pero el muchacho seguía recordando feo la parte vergonzosa de la mujer gorda; el mal olor continuaba cubriendo el mundo.

Entonces decidió marchar al Arayá.

Del Arayá nacía el amanecer; en el Arayá se detenía la luz, siempre, durante el crepúsculo, así estuviera nublado el cielo. Ese resplandor que ya salía de la nieve misma y de las puntas negras de roca, ese resplandor, pues, llegaba a lo profundo. No quemaba como el sol mismo la superficie de las cosas, no transmitía, seguro, mucha fuerza, mucha ardencia, pero llegaba a lo interno mismo del color de todo lo que hay; a la flor su pensamiento, al hombre su tranquilidad de saber que puede traspasar los cerros, hasta el mismo Arayá; al muchacho, a él, a Santiaguito, saber que la mujer sufre, que el pensamiento hace que la mujer sea más que la estrella y como la flor amarilla, suave, del sunchu que se desmaya si el dedo pellejudo del hombre sucio la toca. Al Arayá, únicamente los hacendados que habían hecho flagelar a la gente no lo entendían. Así era («La huerta», 1983, pp. 158-159).

De nuevo el uso del adjetivo funcionando como adverbio («recordando feo»), la anteposición de los complementos del verbo, de manera que la frase puede entenderse, pero queda desordenada («al muchacho, a él, a Santiaguito, saber que la mujer sufre...», «Al Arayá, únicamente los hacendados...»), la introducción de muletillas o locuciones con una función fática, que interrumpen continuamente el discurso...
Como opina Escobar, este rescate del quechua a través del español revela el mundo que este idioma plantea, de una forma latente, honda, radical:

De esta manera la relación translingüística actualiza el mensaje quechua, hace presente lo que no está a la vista; hay una correlación entre los dos términos de la ecuación: el castellano es lo presente y el quechua la lengua copresente, merced a la organización de los rasgos de la literaridad arguediana (1981, p. 173).

Quisiéramos ahora recapacitar brevemente sobre las fuentes de las que bebe Arguedas para transformar así el castellano, las cuales coinciden con la forma de expresividad que él se propone legitimar. Esto es, fijándonos en qué elementos selecciona para su creación de ese español artificial, estaremos descubriendo cuáles son, en su opinión, los componentes decisivos en la especificidad idiomática y cultural quechua.

Ya indicamos cómo una de esas categorías que él trata de rescatar a través de este lenguaje es la pervivencia de una visión mágica y trascendente sobre la realidad. Para reflejar esto en su redacción, echa mano de determinados recursos como son la supresión del artículo y, también, la utilización totalmente libre del adjetivo. Nos parece que ambos mecanismos formales consiguen dotar a la palabra de una amplitud semántica que supera la concreción y el afán catalogador propios de la mentalidad analítica. Por ejemplo, al usar el adjetivo desvinculado del sustantivo, se le está dando a la cualidad una categoría esencial, que rompe con la estructura de pensamiento en la cual lo cualitativo es algo secundario con respecto a lo nominal. Al considerar que el vocablo «bonito» tiene ya entidad por sí mismo, se produce esa eliminación de las fronteras entre lo abstracto y lo concreto que ya mencionamos. En el fondo late, como decimos, una percepción «simpatética» de la realidad, en la cual imperan las leyes de la analogía, fundamental para la cosmovisión mágica y religiosa de estas sociedades.

\section{Hacia la oralidad a través de la escritura}

Otra de las bases de la tradición indígena que este escritor privilegia en su construcción de ese lenguaje narrativo es la presencia de la oralidad. Como sabemos, el quechua es una lengua esencialmente oral. El propio Arguedas expondría en varias ocasiones la necesidad

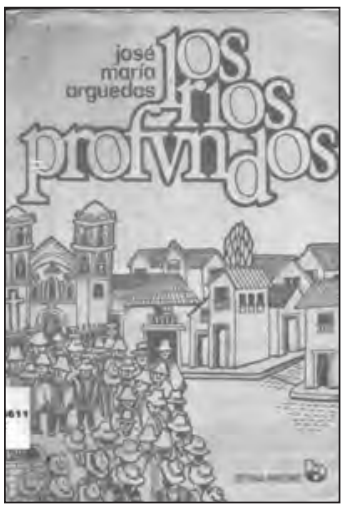

a influencia de lo quechua en la narrativa de Arguedas: un acercamiento a sus relatos GRACIA MORALES 
5

Por ejemplo, en «Un método para el caso lingǘstico del indio peruano», publicado por primera vez en Historia. Revista de Cultura, $\mathrm{n}^{\circ}$ 6, enero-junio de 1944. Asimismo puede encontrarse en Anthropos Suplementos, pp. 55-58 (recogido en la bibliografía).

6

Este libro, donde se recoge toda la producción poética en quechua de Arguedas, fue compilado por Sybila Arredondo editado en 1972, por el Instituto Nacional de Cultura. Algunos de los textos que aparecen en él ya habían sido publicado con anterioridad: Túpac Amaru Kamaq Tayłanchisman. Haylli-taki (A Nuestro Padre Creador Túpac Amaru. Himno-canción) (Lima, Salqantay, 1962); «Oda al Jet» (Zona Franca (Caracas), n ${ }^{\circ} 25$ septiembre de 1965); y Qollan, Vietnam Liqtaman (Al pueblo excelso de Vietnam) (Lima, Federación de Estudiantes de la Universidad Agraria, 1969)

7

En la edición de los Relatos completos (1983), en Anthropos Suplementos (1992) o en el libro Qepa Wiñaqu... Siempre. Literatura y antropología (2009).

La influencia de lo quechua en la narrativa de Arguedas: un acercamiento a sus relatos

GRACIA MORALES de elaborar un alfabeto para representar los fonemas quechuas, de tal modo que el indio pudiera escribir y leer en su propia lengua ${ }^{5}$. Él ya realizó esta labor de escritura en poesía, cuya producción se encuentra agrupada en Katatay $^{6}$; pero en narrativa sólo utilizó este idioma en una ocasión: en el relato «El sueño del pongo", publicado en la revista limeña Saqantay, en 1965 y recogido posteriormente en varias compilaciones ${ }^{7}$.

No obstante, el tema sobre el que queremos reflexionar ahora es sobre cómo se propone ese autor transmitir al español determinadas características que la oralidad impone sobre el quechua; es decir, en este caso no se trataría tanto de «quechuizar» el castellano, sino de encontrar en éste los mecanismos que genera su uso oral y potenciarlos de tal modo que se le esté acercando al modo de comunicación indígena. En este sentido, Martin Lienhard denominó a este tipo de textualidad como «escritura oral», afirmando que consistiría en «la producción de un lenguaje «oral» ficticio, que evoque de alguna manera el lenguaje oral auténtico. Un lenguaje escrito que constituya, a los ojos-oídos imaginarios del lector un equivalente del lenguaje oral» (1990, p. 109).

Una de las estrategias que nos producen esa sensación de estar en contacto con una tradición popular, transmitida de viva voz, es el hecho de que tanto los personajes como el narrador tiendan a explicitar la base oral de sus conocimientos o sus suposiciones. Es bastante habitual la introducción de verbos que enuncian esa procedencia, sobre todo, «decir»y «contar»:

El tayta Ak'chi es un cerro que levanta su cabeza a dos leguas de Ak'ola; diez leguas, quizá veinte leguas mira el tayta Ak'chi; todo lo que él domina es de su pertenencia, según los comuneros ak’olas. En la noche, dicen, se levanta a recorrer sus tierras, con un cuero de cóndor sobre la cabeza, con chamarra, ojotas y pantalón de vicuña; alto es, dicen, y silencioso; anda con pasos largos, y los riachuelos juntan sus orillas para dejarle pasar («Los escoleros», 1983, p. 40).

Y recordé las historias que contaban los comuneros sobre los cerros, las piedras grandes, los ríos y las lagunas.

- De tiempo en tiempo, dice, sienten hambre y se llevan a un mak'tillo; se lo comen enterito y lo guardan en su adentro («Los escoleros», 1983, p. 51).
El chico se fue al zaguán. «Lloraba más grande que estos cerros, Doña Gabriela. Así dicen que la lágrima se puede llevar los cerros. Se pueden llevar, es cierto; a mí también». Fue hablando el muchacho («El horno viejo», 1983, p. 148).

¿Qué es vicio? Dicen. Vicio es gozar más de lo debido y como no es debido. Pero ahí está el goce grande, hijo, el goce que te quema el hueso iy uno se revuelca en lo más dulce como en ceniza del demonio! Así estamos en la sierra. En la costa dicen que es pior. Yo digo que no. («Don Antonio», 1983, p. 175)

No obstante, además de explicitar la utilización de una tradición no escrita, lo que nos parece más interesante es constatar cómo la configuración del propio discurso narrativo se ve afectada por esa cualidad «sonora». Queremos ahora resaltar los mecanismos formales que el autor utiliza para edificar esa «escritura oral» de la que nos hablaba Martín Lienhard. Uno de ellos es la transcripción fonética de la forma en que los personajes pronuncian determinados vocablos, reproduciendo su sonido, no su grafismo. Este recurso, utilizado ya con cierta asiduidad en la narrativa anterior, con el fin de individualizar el habla de un determinado grupo social, cobra en estos cuentos un carácter especial pues se les reproduce sin signarlos como nonormativos. Esto es, mientras en las novelas «realistas» del siglo XIX y principios del $\mathrm{XX}$, cuando se incluía una «incorrección» de este tipo se la hacía aparecer en cursiva o entrecomillada, en los textos arguedianos este discurso popular es recogido sin rupturas con respecto al normativo. En el fondo, como apunta Lienhard, en dicha elección se encuentra presente la pretensión arguediana «de proporcionar un 'estatus' literario a lenguajes localmente mayoritarios (el quechua en los pueblos de la sierra centro-sureña, los sociolectos populares de la costa), pero ignorados por la narrativa escrita» (1990, p. 110).

En «Agua», por ejemplo, se produce un intento claro de reproducir la confusión entre vocales abiertas y cerradas, conectándolo con el sistema vocálico quechua: «endios» por «indios», «sigoro» por «seguro», «nu» por «no», etc... Y en el cuento "Don Antonio» lo que se recoge es el habla popular de la gente de la costa: «pa'que», «qui'así», «nu'hay», «nu'han bajado», «d'iuno», «quieticita», «nu'está»... 
Otro de los momentos en los que Arguedas recoge el habla del pueblo andino, mezclando castellano con quechua, es cuando introduce canciones tradicionales. Muchos autores han destacado ya ese rasgo como algo específico de la narrativa arguediana. No en todos sus relatos se concreta esta tendencia: se da principalmente en los cuentos de Agua ( «Agua», «Los escoleros» y «Warma kuyay») $\mathrm{y}$ también en algunos posteriores como «El forastero», «El ayla»y «Don Antonio».

En opinión de Rama la introducción de estos materiales cumple una doble función: por una parte, «la tradicional de la novela regionalista, que utiliza la canción o el dicho popular como elemento de tipificación y de ambientación realista», pero también sirven como «ejes de traslación para facilitar el pasaje de un campo cultural con sus formas artísticas establecidas, a otro, más sugerido que presentizado, en que ellas carecen de virtualidad» (1976, p. 27). Es decir, en esas canciones se refleja, de forma directa, el pensamiento propio de la sociedad indígena, sin necesidad de adaptarlo a la mirada occidental.

Ahora bien, nos parece importante señalar también lo que estos cantos pierden o sacrifican al aparecer traducidos al español $\mathrm{y}$ en un código escrito. Considerar que, al insertarlos en el relato, Arguedas está consiguiendo revelar totalmente lo que estos suponen para la comunidad que los ha creado, sería disminuir su significación según los parámetros de una lectura occidental. Lo que queremos indicar es que el mecanismo habitual de elocución de esas letras, la recitación oral o el canto acompañado de música, resultan vehículos imprescindibles para quien las produce. Al trasladarlas a un registro escrito y a otra lengua, se están modificando una serie de componentes fundamentales: la recepción colectiva pasa a ser individual, no se establece una relación de inmediatez entre el/los emisor/es y su auditorio, se elimina el marco espacio/temporal, preconcebido y necesario en la elocución indígena, etc. En nuestra opinión, la «lectura» de estos textos está ofreciéndonos una visión sesgada de lo que ellos simbolizan en la realidad quechua a la que pertenecen. En ese proceso transculturador, por el cual son despojados de todos esos elementos reseñados más arriba (los cuales dependen en última instancia de su reproducción oral), lo que termina quedando es un tipo de discurso que, si bien nos produce un cierto extrañamiento, como suponía Rama, sólo revela una versión empobrecida y falseada de sus implicaciones en el mundo cultural quechua. En este sentido, apunta con lucidez el crítico Noé Jitrik:

[...] a la vez, los poemas son quechuas, pero aparecen traducidos, lo que supone un conflicto en la medida en que indica un límite en el universo de lecturas; la musicalidad implicada es la original quechua, pero se los presenta traducidos; la consecuencia es que, frente a una pérdida del referente oral, hay un rescate del código escrito, y en él, de una búsqueda, o sea, de una investigación permanente que afectaría la escritura y que corroboraría lo que se ha señalado en el primer cuento, a saber: otra limitación al realismo, en virtud de la existencia de un destinatario: el lector es castellano (1983, p. 91).

Así pues, ciertamente, el receptor occidental sólo está asumiendo un porcentaje muy reducido de ese espacio significativo que Arguedas conoce y al que nos asoma a través de su narrativa.

No obstante, a pesar de estas limitaciones, queremos volver ahora sobre el tema que veníamos desarrollando: los recursos utilizados por Arguedas en su intento de construir una «escritura oral». Además de los ya señalados, consideramos que existen otra serie de mecanismos discursivos que favorecen esa pretensión.

Uno de ellos radica en la forma en que se presentan los diálogos. Existe una clara pretensión de darles tal inmediatez que, como receptores, nos sentimos impulsados más hacia una especie de escucha virtual que a una lectura; parece como si fuesen voces reales lo que esas intervenciones nos ofrecen. Esto queda reflejado en las continuas expresiones con función fática que son incluidas durante dichos parlamentos. Ya hicimos mención de esta tendencia al referirnos al tipo de discurso que solían emplear los personajes arguedianos: suelen repetirse los «pues», "¿oyes?», «¿Sabes?», «Digo...», «¿Acaso?»... Con estas breves inserciones en los parlamentos, se está produciendo una clara apelación a ese receptor/oyente quien, si en un principio se halla concretado en el interlocutor que acompaña al hablante en ese momento del relato, finalmente llega también a afectar al lector real: éste,
La influencia de lo quechua en la narrativa de Arguedas: un acercamiento a sus relatos GRACIA MORALES 
aun quedando fuera de la narración, parece hallarse también «a la escucha».

Esta pretensión de poner al lector «a la escucha», se evidencia aún más en otra estrategia, que nos parece interesante reseñar: el hecho de que en esos fragmentos de diálogo, no se nos explicite quién interviene en cada momento. Es decir, se produce una eliminación de los llamados verba dicendi, de forma que las intervenciones de los personajes no parecen funcionar como instancias de un discurso escrito, sino como si estuvieran siendo reproducidas directamente, sin la mediación explicativa del narrador.

Esta característica se evidencia, sobre todo, en algunos relatos donde aparecen asiduamente personajes dialogando. En «Don Antonio", integrante de Amor mundo, por ejemplo, se utiliza mucho este tipo de discurso, llegando a registrarse cincuenta y una intervenciones, casi siempre de don Antonio o del niño Santiago, de las cuales sólo diez se encuentran acompañadas de alguno de esos verba dicendi. Queremos ahora recoger algunos ejemplos de ese tipo de presentación directa de las voces de los personajes que, en ocasiones, quedan en un total anonimato, funcionando a modo de un coro colectivo. Eso sucede en el siguiente fragmento de «El ayla»:

- Van a hacer sus asquerosidades en el cerro estos indios.

- La bacanal de cada año.

- Y el cura nada dice.

- Es hijo de indio desconocido. Lo recogió el Obispo.

- El cura también aprovecha después.

- Pero en el campo, como animal, es distinto. El cura no entra en eso.

- Ya no es indio indio.

- En el campo, como animales, así como chanchos.

- ¡Qué saben esos de amor, ésos!

- Todo en tropa, y eso que muchos de ellos ya saben leer...

- No, ésos ya no van, dicen. Se avergüenzan de esta cochinada.

- Algunos, algunos, van (1983, p. 165).

En otras ocasiones, los interlocutores sí que tienen una identidad definida, que debemos adivinar a través de lo que dicen o del modo en que se expresan. Así pues, el narrador no nos explicita quién habla, sino que es el propio discurso el que nos da la clave para situar esa voz y también para saber a quién se está dirigiendo. Como muestra recogemos un texto de «Warma kuyay» y otros dos de «El forastero»:

- ¡Justinay, te pareces a las torcazas del Sausiyok'!

- ¡Déjame, niño, anda donde tus señoritas!

- ¿Y el Kutu? ¡Al Kutu le quieres, su cara de sapo te gusta!

- ¡Déjame, niño Ernesto! Feo, pero soy buen laceador de vaquillas y hago temblar a los novillos de cada zurriago. Por eso Justina me quiere. (1983, p. 79)

- Tienes los ojos buenos -le dijo él.

- ¿Buenos?

- Y negros. ¿Qué eres?

- ¿No sabes? No pareces mexicano, ni panameño, ni de Nicaragua... A esos los conozco en seguida. ¿De dónde?

- Soy del Perú.

- ¿A cuántas horas de avión está?

- Diez.

- No importa. Acompáñame. Quiero ver a mi hijo; después bailamos; después te acompaño, a donde quieras.

- Vamos, María.

- ¿Cómo sabes que es mi nombre?

- Claro, pues; aquí, con lo que eres y lo que yo soy... - Así hablan los... ¿De dónde dijiste que eres?

- No importa. Vamos. (1986, pp. 80-81)

- Eres bella -le dijo él.

- Pero sucia.

- Del rostro, un poco de tus cabellos. Así son ellas, las indias de mi pueblo.

- ¿Qué es eso, y qué es el cóndor?

- India es una hembra que sufre, las que me criaron; cóndor es un animal negro, de alas grandes, que sufre más.

- ¿Por qué?

- A causa de mí.

- ¡Anda «bolo»! Será por mí. Ya visté al negro. ¿Tienes un quetzal o un collar?

- Cinco.

- No. Es mucho. Dame dos. El negro es bueno. Abuelo del chico. Dos quetzales vale su buena voluntad. No sale nunca del hotel.

- ¿Oye toda la noche?

- No, señor. Duermo sentado. Esa cama tiene suciedad. Quema más que un carbón encendido. Esta me trajo de Puerto Barrios. Llega borracha a esta hora, más o menos. Entra sola. ¿Por qué lo ha traído a usté? - Es cóndor. ¿No has oído? Dice que sufre.

- Pobre perra. Crees todavía saber quién es inocente. Voy a recibir el billete de cinco. 
- Muy bien amigo. De todas partes viene la oscuridad hasta este cuarto. Pero ella tiene hermosa luz en su ojo, María (1986, pp. 82-83).

Se puede destacar cómo, en este último fragmento, la entrada a la conversación del «abuelo del chico» se produce sin previo aviso por parte del narrador, lo cual produce en el lector una primera reacción de extrañeza, hasta que consigue situar esa voz por sí mismo.

Podríamos preguntarnos ahora cuáles son las consecuencias ideológicas de ese intento de construir un texto cercano a la oralidad. En nuestra opinión, a través de su plasmación de esta forma comunicativa, se está privilegiando toda una serie de instancias que se reúnen en ese código verbal. Ya hemos dado cuenta de alguna de ellas: por ejemplo, el hecho de que se le esté proporcionando un valor literario a los sociolectos que había sido normalmente excluidos de ese terreno. A ello se refiere Rama en su estudio de Los ríos profundos, y de ahí surge su definición de esta novela como «ópera de los pobres» (1985). Mediante esta narrativa, se le otorga la posibilidad de explicarse, de expresarse y de permanecer a los normalmente ajenos a «la ciudad letrada». Otra implicación promovida por esa utilización de lo oral-popular, se encuentra en el rescate de su raíz colectiva. Según creemos, se produce una recuperación de la voz de la comunidad, a la vez que se está ensalzando el valor del pasado de un pueblo como base para sustentar su presente. Esa preeminencia del componente colectivo sobre lo individual ya fue señalada por Vargas Llosa, por ser una de las características de la producción arguediana:

En realidad, el personaje central es siempre colectivo: los comuneros en Yarwar Fiesta, la ciudad de Abancay en Los ríos profundos, la muchedumbre larval y sub-humana de los penados comunes en El Sexto. El colectivismo aparece en sus novelas y cuentos, a la vez como una característica propia de la comunidad que él evoca y como un procedimiento formal. Es una prueba más de la fusión que se opera en la obra de Arguedas de dos realidades: la social, la literaria (1964, p. 7).

Por otra parte, los investigadores de la obra arguediana ya han evidenciado la importancia que este autor le concede a la re- cuperación de la memoria cultural indígena, tanto en su faceta de escritor como en sus estudios de etnología. Hay que apuntar, pues, brevemente, cómo privilegiar formalmente la oralidad en sus relatos es otro modo más de hacer legítima la voz colectiva quechua y la identidad cultural que de ella se desprende, rescatando y valorizando sus formas de transmisión tradicionales.

\section{Bibliografía}

Aleza Izquierdo, Milagros (1997), Una cultura sumergida: Aspectos lingüísticos de la narrativa de José María Arguedas, Valencia, Tirant lo Blanch / Universidad de Valencia.

Arguedas, José María (1938), Canto kechwa, Lima, Compañía de Impresiones y Publicidad.

Arguedas, José María (1973), Cuentos olvidados, Lima, Imágenes y Letras.

Arguedas, José María (1983), Relatos completos, Madrid, Alianza.

Arguedas, José María (1986), Los ríos profundos. Cuentos escogidos, Santiago de Chile, Ayacucho.

Arguedas, José María (1992), «La novela y el problema de la expresión literaria en el Perú», Suplementos Anthropos, 31 (José María Arguedas. Una recuperación indigenista del mundo peruano; Rovira, José Carlos (ed.)), pp. 31-35.

Arguedas, José María (2009), Qepa Winaq... Siempre. Literatura y antropología, Madrid, Iberoamericana/Vervuert.

Bendezu Aibar, Edmundo (1974), "Yawar Fiesta: espejo quechua» de José María Arguedas», Insula, 332-333, pp. 9 y 23.

Castro Klaren, Sara (1973), El mundo mágico de José $M^{a}$ Arguedas, Lima, Instituto de Estudios Peruanos.

Escobar, Alberto (1981), José María Arguedas, el desmitificador del indio y del rito indigenista, Chicago, The University of Chicago. Center for Latin American Studies.

Jitrik, Noé (1983), «Arguedas: reflexiones y aproximaciones», Revista Iberoamericana, 122 (dedicado a José $\mathrm{M}^{\mathrm{a}}$ Arguedas), pp. 83-95.

Lienhard, Martin (1990), Cultura andina y forma novelesca. Zorros y danzantes en la última novela de Arguedas, Lima, Horizonte.

Morales, Leónidas T. (1993), Figuras literarias, rupturas culturales (Modernidad $e$
La influencia de lo quechua en

la narrativa de Arguedas: un

acercamiento a sus relatos

GRACIA MORALES 
identidades culturales tradicionales), Santiago de Chile, Pehuén.

Rama, Ángel (1976), «José María Arguedas trasculturador», en José María Arguedas, Señores e indios, Buenos Aires, Arca/ Calicanto, pp. 7-38.

Rama, Ángel (1985), Transculturación narrativa en América Latina, México, Siglo XXI.

Rowe, William (1973), «Mito, lenguaje e ideología en Los Ríos Profundos», Textual (Lima), 7, pp. 2-12.
Rowe, William (1979), Mito e ideología en la obra de José María Arguedas, Lima, Instituto Nacional de Cultura.

Vargas Llosa, Mario (1964), «José María Arguedas descubre al indio auténtico", Visión del Perú, 1, pp. 3-7.

Fecha de recepción: 29/07/2012

Fecha de aceptación: 22/10/2012 


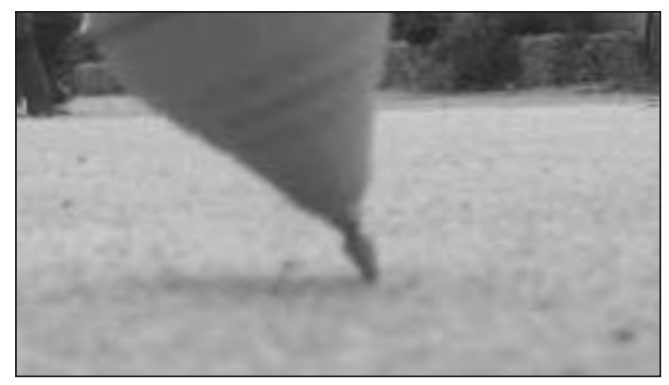

\section{Zumbayllu}

Encordelé mi hermoso zumbayllu y lo hice bailar. El trompo dio un salto armonioso, bajó casi lentamente, cantando por todos sus ojos. Una gran felicidad, fresca y pura, iluminó mi vida. Estaba solo, contemplando y oyendo a mi zumbayllu que hablaba con voz dulce, que parecía traer al patio el canto de todos los insectos alados que zumban musicalmente entre los arbustos floridos.

Los ríos profundos 